\title{
Gas Hydrate in Nature
}

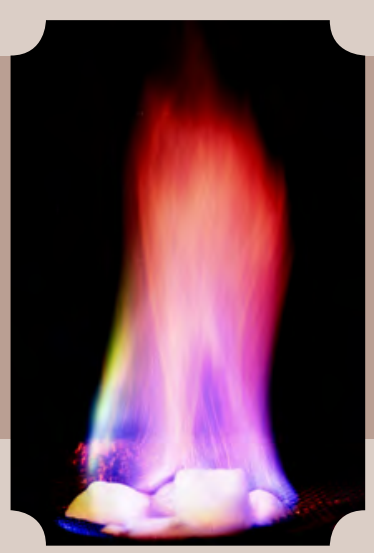

Gas hydrate consists of water molecules that form cages enclosing gas molecules. Most naturally occurring gas hydrate contains methane, which is the natural gas that is piped into many homes. In addition to methane, gases like ethane, carbon dioxide, and hydrogen sulfide are sometimes incorporated into gas hydrate. Gas hydrate represents a highly concentrated form of methane. For the most common crystal structure (fig. $1 A$ ), 1 cubic inch $\left(\mathrm{in}^{3}\right)$ of gas hydrate will leave behind as much as $0.8 \mathrm{in}^{3}$ of water and $180 \mathrm{in}^{3}$ of methane when the hydrate breaks down at room pressure and temperature.

Studies of gas hydrate originally focused on ensuring the flow of oil and gas in pipelines, which often clogged with gas hydrate. Since the 1980 s, there has been strong international interest in naturally occurring gas hydrate (fig. $1 B$ ), which is widespread on Earth and holds an estimated 1,800-12,400 gigatons of carbon, corresponding to $3-24.8 \times 10^{15}$ cubic meters $(106,000-876,000$ trillion cubic feet or TCF) of methane (Boswell and Collett, 2011). For comparison, the United States used an estimated 27.49 TCF of natural gas in 2016 (U.S. Energy Information Administration, 2017).

\section{Marine Gas Hydrate}

In nature, the sediments of deep marine continental margins host nearly 99 percent of the world's gas hydrate, typically at water depths of $500 \mathrm{~m}$ (approximately 1,640 ft) and greater. The sediments on continental margins often contain substantial concentrations of organic carbon, which is used by microbes to produce methane. This methane, as well as older microbial methane or even methane that migrates upward from deep conventional gas reservoirs, can combine with sediment pore waters to form gas hydrate beneath the sea floor. Gas hydrate also sometimes forms directly on the sea floor where fluids leak into the ocean at seep sites, but such deposits are not considered an important component of the global gas hydrate inventory.

In continental margin sediments, the natural pressure and temperature conditions mean that the gas hydrate zone thins out upslope and thickens downslope, reaching hundreds of meters (100 m equals $328 \mathrm{ft}$ ) of thickness as water depths increase (fig. 2). In many locations, field studies show that only

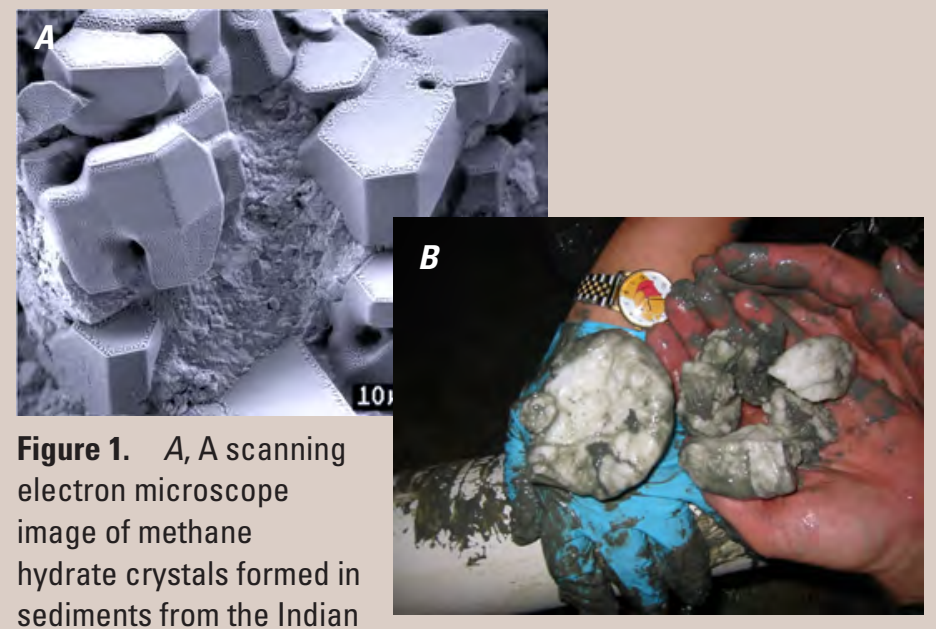

Ocean. The 10 micrometer $(\mu \mathrm{m})$ scale is approximately $4 / 10,000$ ths of an inch or a quarter of the width of a human hair. $B$, Chunks of white gas hydrate with gray sediment recovered from beneath the sea floor of the Gulf of Mexico.

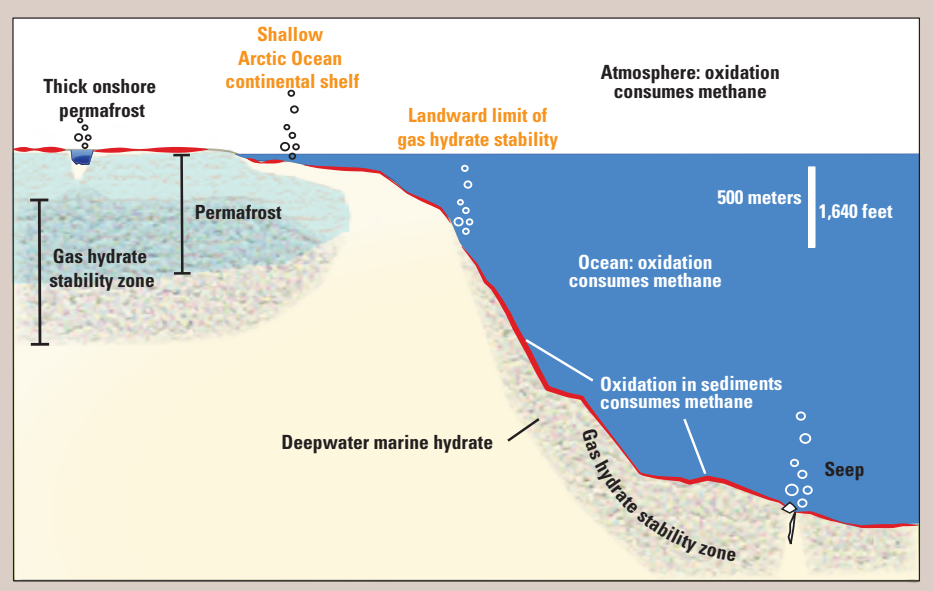

Figure 2. Schematic cross section showing gas hydrate within and beneath permafrost (left side) and in deepwater marine sediments (right side). The locations described in orange are the most susceptible to climate processes that can affect the stability of methane hydrate deposits. Oxidation can destroy methane in the sediments, in the water column, and in the atmosphere. 
a small fraction (less than 5 percent) of the sediments host gas hydrate, which is sometimes concentrated in specific layers or in fractures.

Deepwater marine gas hydrate occurs on all continental margins of the United States (fig. 3). The U.S. Bureau of Ocean Energy Management (BOEM) estimates that an average of 21,444 TCF of methane is present in gas hydrate in sediments of the northern Gulf of Mexico. For the U.S. Atlantic Ocean margin, the estimate is 21,702 TCF, and for the Pacific margin (excluding Alaska) the assessment yields an average of 8,192 TCF (Bureau of Ocean Energy Management, 2012).

For more than two decades, deepwater gas hydrate has been the focus of ocean drilling expeditions led by scientific consortia, governments, and private companies. Among the best studied locations are the northern Gulf of Mexico and areas offshore of Oregon; Vancouver, Canada; India; Japan; South Korea; and China.

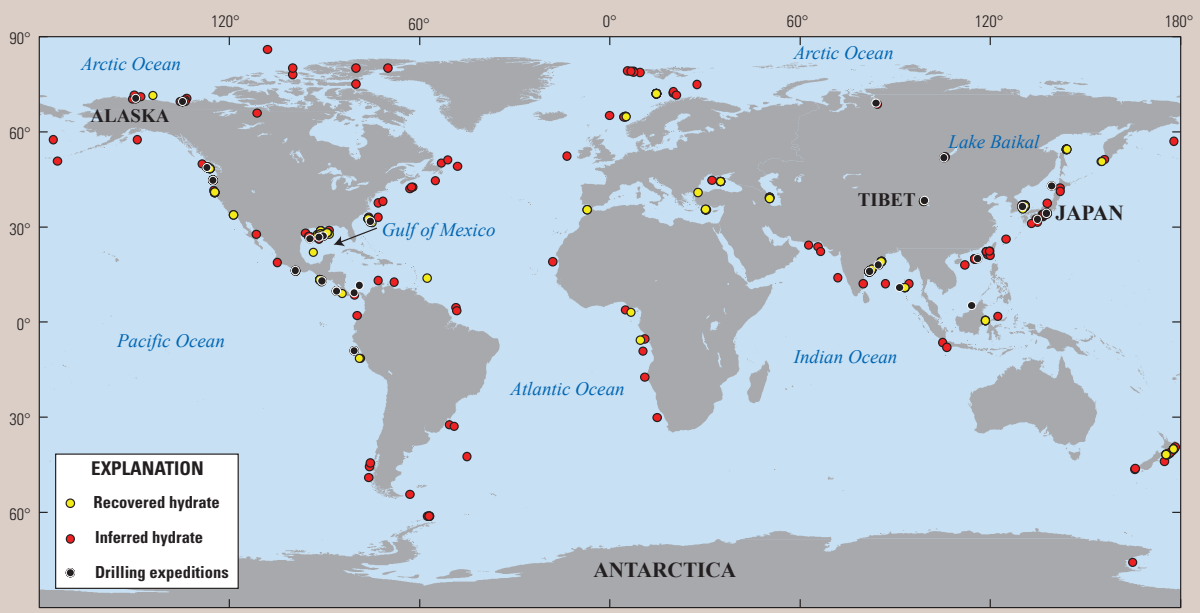

reservoirs. Permafrost-associated gas hydrate has been extensively studied in northern Alaska and in the Mackenzie Delta of the Canadian Arctic (Collett and others, 2009).

\section{Prospecting for Gas Hydrate}

Although gas hydrate is widespread, finding the deposits can be challenging. In marine settings, researchers sometimes identify gas hydrate by mapping a seismic reflector that marks the base of the gas hydrate stability zone in the sediments (fig. 4). Where this reflector is found, gas hydrate is present in the overlying sediments; however, gas hydrate is also sometimes present in places that lack this reflector.

Electromagnetic surveys are sometimes combined with seismic imaging in prospecting for gas hydrate. Like ice, gas hydrate acts as an electrical resistor, making it harder for electrical current to flow through sediments. Electromagnetic surveys are therefore highly effective at finding gas hydrate in some marine settings.

Electromagnetic and seismic surveys are typically conducted at the regional scale. At a local scale, boreholes drilled in the sea floor or permafrost provide direct access to the sediments. Special instruments are deployed in boreholes to infer the composition of the sediment layers, the amount of gas and gas hydrate, fracture patterns, and other characteristics.

\section{Gas Hydrate and Energy Resources}

Gas hydrate traps large amounts of methane in compact deposits at shallower and more accessible depths than most
Figure 3. Map showing locations where gas hydrate has been recovered, where gas hydrate is inferred to be present on the basis of seismic data, and where gas hydrate drilling expeditions have been completed in permafrost or deep marine environments, also leading to recovery of gas hydrate.

\section{Permafrost-Associated Gas Hydrate}

Globally, only a small fraction of natural gas hydrate is present in areas with thick permafrost, which refers to sediments that remain permanently frozen because of profound cooling of the ground during glacial events occurring over the past few hundreds of thousands of years. In the United States, most of the remaining continuous permafrost is onshore on the Alaskan North Slope. Some permafrost that originally formed onshore during the last ice age has been flooded by sea level rise during the past 15,000 years and now persists offshore beneath the shallow waters of the Arctic Ocean continental shelf (fig. 2).

In permafrost settings, temperature and pressure conditions appropriate for pure methane hydrate to be stable occur in the lowermost part of the frozen sediments and in the uppermost part of the underlying, unfrozen sediments. Permafrost-associated gas hydrate probably formed when gas and water froze in place during ice-age cooling events. Prior to the cooling events, most, but not all, of the gas contained in permafrost-associated gas hydrate deposits may have migrated upward from deep conventional gas conventional gas reservoirs. For this reason, there has long been interest in gas hydrate as a potential energy resource. Hydratebearing sands are a particular target for energy studies because of the high concentrations of gas hydrate sometimes found in these sediments (fig. 5). Existing technology is well-suited to

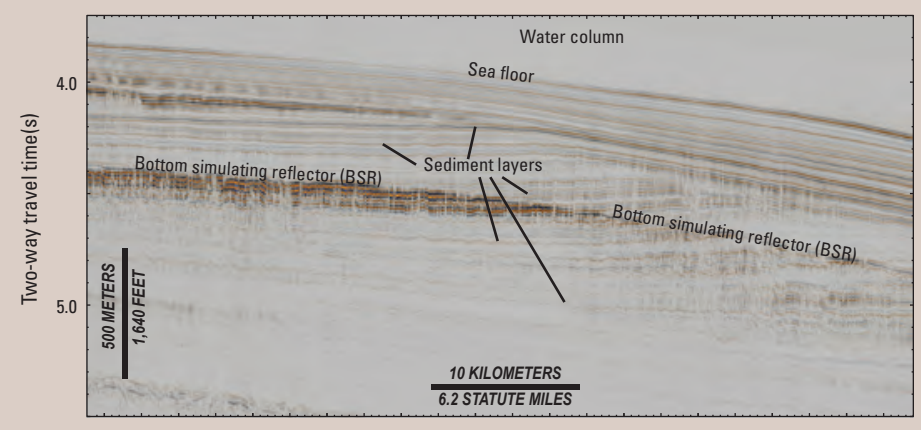

Figure 4. A seismic image acquired by the U.S. Geological Survey on the U.S. Atlantic margin about 300 kilometers (186 statute miles) offshore Delaware in 2014 shows the upper layers of sediment in the sea floor and a strong bottom simulating reflector (BSR) that crosses sediment layering. Sediments shallower than the BSR may host gas hydrate, while sediments deeper than the BSR may have gas bubbles in the pore space. Water depth on the left side of the image is 2,850 meters ( 9,350 feet). Image courtesy of D. Hutchinson (USGS). 


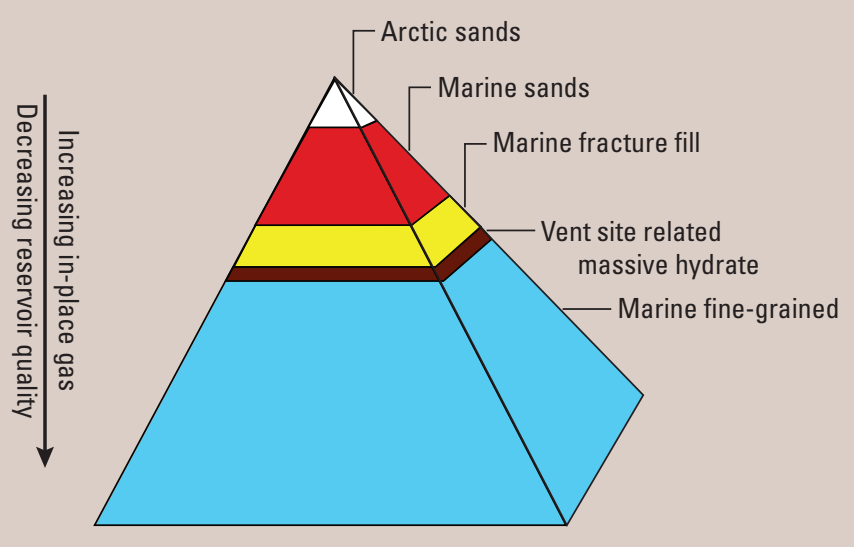

Figure 5. Gas hydrate resource pyramid showing the relative proportion of methane trapped in these deposits in each setting. Although gas hydrate in fine-grained marine sediments contains the most methane, these deposits are unlikely to be exploitable as an energy resource. Modified from Boswell and Collett (2011).

extracting methane from hydrate in sandy sediments (Boswell and Collett, 2011).

As of 2017, gas hydrate is not exploited commercially as a source of natural gas. Because the resource is not yet proven as commercially viable, there are no known reserves of methane in gas hydrate. Short-term research tests of gas production from gas hydrate have been conducted in permafrost areas in Canada and the United States and in the deepwater marine environment offshore of Japan and China. Longer duration (months to more than a year) research production tests are planned for the future, and some countries hope to achieve commercial-scale production of gas from hydrate within the next several decades.

The most common technique for producing gas from gas hydrate lowers the pressure (depressurization) within the sediments, thereby triggering breakdown (dissociation) of the gas hydrate into gas and water (Collett and others, 2009). Such depressurization can be completed with existing technology. Because of the thermodynamic characteristics of gas hydrate, there is no danger that dissociation will continue unabated once it starts. In fact, hydrate-bearing sediments sometimes have to be heated to drive continued release of gas after depressurization starts. An additional challenge for production is managing large amounts of water released when gas hydrate breaks down.

\section{Gas Hydrate and the Environment}

Gas hydrate is stable only within specific ranges of temperature and pressure. As average atmospheric and ocean temperatures increase, gas hydrate in permafrost and deep marine settings may break down and release the trapped methane. Much of the liberated methane is likely to remain in the sediments. Methane that escapes from the sea floor into the ocean (fig. 6) is typically converted to carbon dioxide by micro-organisms, a process that increases the acidity of ocean waters.

About 5 teragrams (Tg; $1.1 \times 10^{10}$ pounds) of atmospheric methane emissions per year is attributed to the breakdown of gas hydrate. This amount of methane is about 1 percent of the annual methane emissions of $555 \mathrm{Tg}$ per year from all natural and anthropogenic sources. Methane is a potent greenhouse gas, and a critical research direction is determining whether

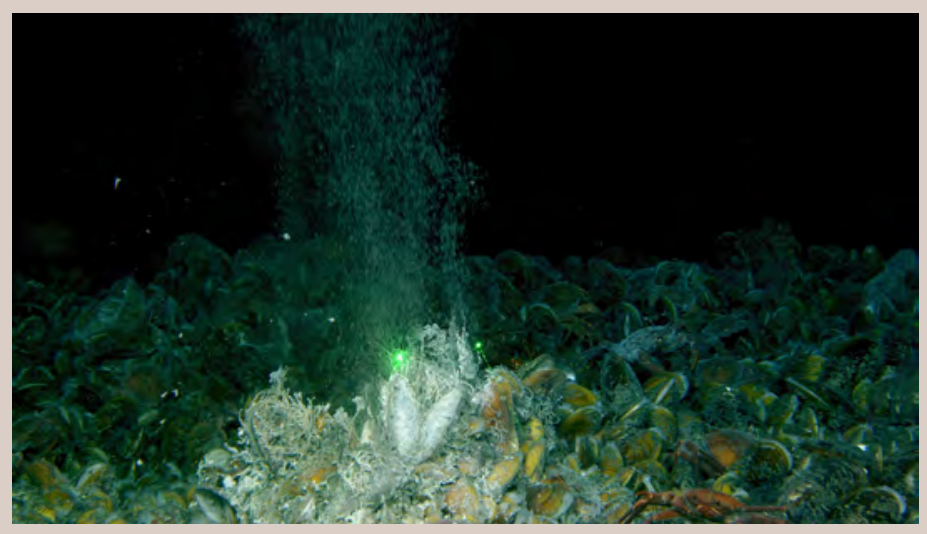

Figure 6. A photograph taken by 0ceaneering Inc. using the Global Explorer remotely operated vehicle shows methane bubble streams emanating from the sea floor within a field of mussels at approximately ( ) 950 meters ( 3,116 feet) water depth $\sim 110$ kilometers ( 68 miles) off the shore of Virginia during a U.S. Geological Survey cruise in 2017. Green laser dots are separated by 10 centimeters ( 3.94 inches).

methane hydrate breakdown is truly contributing methane to the atmosphere now or is likely to do so in the next century or more (Ruppel and Kessler, 2017).

Since at least the last part of the 20th century, methane hydrate has likely been breaking down in two environmental settings: (1) within the sediments of upper continental slopes at water depths of 300-800 m (1,000-2,600 ft) and (2) in locations around the Arctic Ocean where permafrost that was previously onshore has been flooded by sea level rise during the past 15,000 years. Globally, most gas hydrate deposits are so deeply buried that the gas hydrate is likely to be stable for centuries or more under most model scenarios for future warming (Ruppel and Kessler, 2017).

\section{Gas Hydrate and Sea-Floor Failure}

Gas hydrate often is present beneath large-scale submarine slide scars, but there is no evidence that gas hydrate causes seafloor failures. When gas hydrate breaks down, it releases methane gas and water into the surrounding sediments, increasing the internal pressure in the sediments. These conditions can prime slopes for failure if triggered by an earthquake or the addition of too much sediment on the sea floor.

When gas hydrate is present at high concentrations in sediments, it binds the sediment grains, which creates a mechanically strong layer. Gas-charged sediments, which are often found beneath sediments that host gas hydrate, are relatively weak. The layering of sediments with different mechanical strengths might also exacerbate sea-floor failure under certain conditions.

\section{Future Studies}

Several countries are pursuing potential commercialization of gas production from methane hydrate to expand their domestic energy resources. The U.S. Geological Survey participates in national and international expeditions (fig. 7) that advance understanding of natural gas hydrate deposits for energy studies and also assesses the amount of methane trapped in the deposits. The next generation of tests to produce methane from gas 
hydrate is likely to including monitoring to track potential gas escape, ground subsidence, and the amount of coproduced water.

In many places, gas hydrate deposits are still unexplored.

Existing geophysical techniques can identify the deposits, and research will continue to develop new technology to better determine the amount of gas hydrate in sediments. Further deep drilling, characterization of the sediments through the use of borehole instrumentation, and studies on recovered hydratebearing sediments can also advance knowledge.

For environmental studies of gas hydrate, a key challenge remains fingerprinting gas released from methane hydrate degradation so that it can be tracked through the ocean and atmosphere. In addition, scientists are striving to accurately assess the amount and locations of gas hydrate deposits that are susceptible to environmental change over decades, centuries, and millennia.

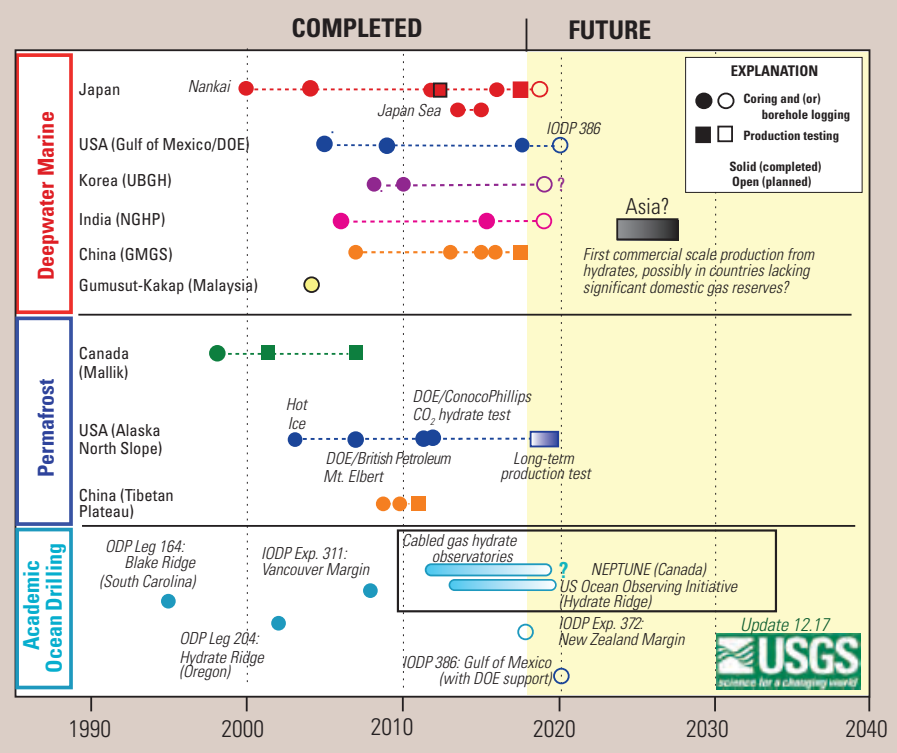

Figure 7. Timeline showing past and future drilling and deep-sea coring and borehole logging expeditions as of late 2017. The goal of the permafrost and deepwater marine programs is to evaluate the potential of gas hydrate as a resource, whereas the goal of the academic ocean drilling programs is to focus on critical research questions related to natural gas hydrate deposits. DOE refers to the U.S. Department of Energy. The academic programs are the Ocean Drilling Program (ODP; 1983-2003), the Integrated ODP (IODP; 2003-2013), and the International Ocean Discovery Program (IODP), which started in 2013. The international marine drilling programs are the Ulleung Basin Gas Hydrates project (UBGH; Korea), the National Gas Hydrates Project (NGHP; India), and the Guangzhou Marine Geological Survey (GMGS; China).

\section{References Cited}

Boswell, R., and Collett, T.S., 2011, Current perspectives on gas hydrate resources: Energy \& Environmental Science, v. 4, p. 1206-1215. [Also available at https://doi.org/10.1039/ COEE00203H].
Bureau of Ocean Energy Management, 2012, Assessment of in-place gas hydrate resources of the lower 48 United States outer continental shelf: Bureau of Ocean Energy Management Fact Sheet RED-2012-01, 4 p. [Also available at https://www.boem.gov/uploadedFiles/BOEM/Oil_and_Gas Energy_Program/Resource_Evaluation/Gas_Hydrates/BOEMFactSheetRED_2012-01.pdf].

Collett, T.S., Johnson, A.H., Knapp, C.C., and Boswell, R., 2009, Natural gas hydrates - A review, in Natural gas hydratesEnergy resource potential and associated geologic hazards, ed. Collett, T.S., Johnson, A.H., Knapp, C.C., and Boswell, R.: American Association of Petroleum Geologists Memoir 89, p. 146-219.

Ruppel, C.D., and Kessler, J.D., 2017, The interaction of climate change and methane hydrates: Reviews of Geophysics, v. 55, no. 1, p. 126-168. [Also available at https://doi.org/10.1002/2016RG000534].

U.S. Energy Information Administration, 2017, Natural gas annual supply and disposition by State: U.S. Energy Information Administration data, accessed December 11, 2017, at https://www.eia.gov/dnav/ng/ng_sum_snd_a_EPG0_VC0_ Mmcf_a.htm.

\section{By Carolyn Ruppel}

The USGS Gas Hydrates Project is supported by the USGS Coastal and Marine Geology Program and the USGS Energy Resources Program.

\section{Further Information:}

Coastal and Marine Geology Program Coordinator

Energy Resources Program Coordinator

U.S. Geological Survey

12201 Sunrise Valley Drive

Reston, VA 20192 USA

Email: webmaster-marine@usgs.gov; gd-energyprogram@usgs.gov

- Overview of the U.S. Geological Survey's Gas Hydrates Project: https://woodshole.er.usgs.gov/project-pages/ hydrates/index.html

- U.S. Geological Survey’s Energy Resources Program gas hydrates site: https://energy.usgs.gov/OilGas/UnconventionalOilGas/ GasHydrates.aspx

- The U.S. Geological Survey's Gas Hydrates Project fact sheet: https://doi.org/10.3133/fs20173079

Any use of trade, firm, or product names is for descriptive purposes only and does not imply endorsement by the U.S. Government. 